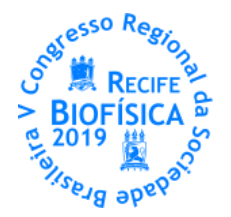

\title{
A INTERDISCIPLINARIDADE DO “MUNDO NANO” Á LUZ DO TEXTO DE DIVULGAÇÃO CIENTIFICA
}

\author{
Ana Paula Conceicão ${ }^{1 *}$, Maria Oliveira ${ }^{2}$, Romildo Nogueira ${ }^{3}$, \\ ${ }^{1}$ Licenciada em Ciências Biológicas e mestra em ensino de ciências pela UFRPE, ${ }^{2,3}$ Professor e pesquisador do Grupo de Estudos de Hermenêutica \\ e Interdisciplinaridade na Formação de Professores (GHIFOP) da UFRPE. \\ *anapaulabioensino@gmail.com
}

\section{INTRODUÇÃO}

Há muito tempo se sabe que a matéria é formada por massa e ocupa um lugar no espaço, e que essa massa se refere ao conjunto ou arranjo de moléculas que graças as suas interações proporcionam os diferentes estados físicos da matéria. Com base nesse conhecimento, foram obtidos importantes avanços na ciência e tecnologia dos materiais (CHAVES, 2002).

Essas invenções tecnológicas permitiram a produção de cristais sintéticos diversos, desde diamantes até os cristais de silício com os quais fabricamos os chips dos computadores e outros materiais com propriedades específicas e otimizadas para aplicações industriais diversas.

Atualmente as Nanociências têm originado diversos conhecimentos, como é o caso da Nanotecnologia tendo um vasto repertório de estudos aplicados a diversas áreas da ciência. Neste "Mundo Nano" ou subatômico, estamos regido por novas leis, por novas interações, e para entendê-lo temos que obrigatoriamente romper os paradigmas estabelecidos durante anos pela física clássica newtoniana e a lógica aristotélica e começar a conceber os novos aspectos trazidos pela física nuclear e a mecânica quântica. Dessa forma, é perceptível que a nova ciência deve está aberta a novas ideias, perspectivas e compreensões de mundos tão diferentes em diferentes níveis e muitas vezes até contraditórios com aquilo em que acreditamos boa parte das nossas vidas.

Na perspectiva escolar, França (2005) relata que a nanociência tem a possibilidade de promover um eficiente diálogo entre disciplinas escolares, propiciando aos alunos uma visão que ultrapasse a visão cartesiana e possibilite uma prática interdisciplinar. Por se tratar de uma escala tão pequena, acaba perpassando por todos os conhecimentos sendo um objeto de estudo interdisciplinar.

De acordo com França (2005) a inserção de temas sobre Nanociências requer uma formação mais sofisticada dos professores e alunos, visto que para a compreensão da Nanociência são necessárias ferramentas mentais e conceituais com alto nível de abstração, que possibilitem aos mesmos, transitar entre estas duas realidades, a macro e a nano, nas quais imperam modelos, conceitos e propriedades distintas.

Para tanto, acreditamos ser o Texto de Divulgação Científica (TDC) um material de apoio, com possibilidades de subsidiar tal ação, pois além de ser um recurso de fácil acesso, é uma forma de familiarizar os alunos com o vocabulário científico e as peculiaridades que envolvem uma pesquisa científica e ainda a grande rotatividade de constantes de produções com publicações recentes. Portanto, o objetivo da presente pesquisa é analisar o TDC como recurso didático para abordar a Nanociência em sala de aula.

\section{MATERIAIS E MÉTODOS}

A coleta de dados da pesquisa foi realizada durante uma Prática Interventiva Interdisciplinar á luz do TDC (PIIN á luz do TDC) seguindo as etapas: 1 - Sequencia Didática Interativa prévia (SDIPrévia), 2- PIIN á luz do TDC, 3- SDI pós-PIIN.

Na PIIN á luz do TDC sobre a Nanotecnologia / Nanobiotecnologia os temas foram trabalhados com diversos recursos didáticos, dentre eles a exposição de slides e textos científicos extraídos do livro Física hoje: uma aventura pela natureza: dos átomos ao Universo do ano de 2007, p. 68-83), e da RDC (Revista de Divulgação Científica) Scientific American Brasil $n^{\circ} 156$, do ano de 2015, p. 27-35.

- Sequência Didática Interativa (SDI)

A Sequência Didática Interativa (SDI) (OLIVEIRA 2013, p.58) foi usada na coleta de concepções prévias e pós a PIIN à luz do TDC, sobre o "Mundo Nano", tendo como pergunta norteadora: Que perspectivas e abrangências, a Nanotecnologia pode trazer na medicina e na pesquisa científica?

A partir das respostas a pergunta, analisarmos as concepções prévias dos licenciandos sobre seus entendimentos de Nanobiotecnologia antes da PIIN, para então depois dessa intervenção, lançar novamente a mesma pergunta, realizando o confronto de tais concepções e analisando-as á luz da Análise de Conteúdo (AC) proposta por Bardin (2009).

Para a coleta de tais concepções foi necessário seguir alguns passos, destacados na tabela:

Tabela 2. Etapas da coleta de dados pré e pós PIIN baseada na SDI.

Tabela 2. Etapas da coleta de dados pré e pós PIIN baseada na SDI.
\begin{tabular}{|c|c|c|}
\hline $\begin{array}{c}\text { Etapas: } \\
\text { Primeira }\end{array}$ & Concepções: Individuais & $\begin{array}{c}\text { Cada aluno individualmente responde a } \\
\text { pergunta norteadora em uma ficha. }\end{array}$ \\
\hline Segunda & $\begin{array}{c}\text { Concepções: } \\
03 \text { Subgrupos }\end{array}$ & $\begin{array}{c}\text { Alunos em grupo elaboram uma } \\
\text { concepção em grupo. }\end{array}$ \\
\hline Terceira & $\begin{array}{c}\text { Concepção: Grupo } \\
\text { sintese final (Concepção } \\
\text { final) }\end{array}$ & $\begin{array}{c}\text { Um membro de cada um dos 03 } \\
\text { subgrupos, foi escolhido para compor } \\
\text { um novo grupo, desse foi elaborada uma } \\
\text { sínteses das concepções }\end{array}$ \\
\hline Quarta & $\begin{array}{c}\text { Confronto das } \\
\text { concepções }\end{array}$ & $\begin{array}{c}\text { Foram expostas para os licenciandos as } \\
\text { duas concepções finais por eles } \\
\text { construídas pré e pós PIIN e analisadas e } \\
\text { discutidas as diferenças entre ambas. }\end{array}$ \\
\hline
\end{tabular}

A PIN á luz do TDC: esta prática mais as duas SDI, totalizaram quatro encontros de $2 \mathrm{~h} /$ aulas, resultando em $8 \mathrm{~h} /$ aulas todo o processo. Todos os encontros foram embasados nos materiais entregues previamente em uma pasta personalizada. A partir do plano de aula elaborado para os quatro encontros, foi possível a discussão das características acerca do "Mundo Nano", utilizando uma apresentação em slides (Powerpoint), diálogo com os 
participantes e discussão de alguns TDC sobre tais temáticas com enfoque Interdisciplinar.

\section{RESULTADOS E DISCUSSÃO}

A análise dos dados coletados sobre das concepções dos licenciandos na investigação das contribuições das aulas com abordagens Nanobiotecnológicas na PIIN á luz do TDC foi realizada através da técnica Análise de Conteúdo ( $A C)$

Segundo Bardin (2009), esse tipo de análise é organizado em algumas fases, e são elas: a pré-análise (permitindo a leitura flutuante, escolha dos documentos, preparação do material e referenciação dos índices e a elaboração dos indicadores), a exploração do material coletado, o tratamento dos resultados, a inferência e a interpretação.

A pré-análise foi trabalhada levando em consideração todas as regras citadas; começamos com a leitura flutuante das concepções dos licenciandos durante as SDI, tendo em vista os objetivos, questão de pesquisa e fundamentação já elaboradas previamente. Logo após esta etapa, selecionamos as concepções a serem usadas na pesquisa, pois muitas delas estavam incompletas devido à falta de alguns licenciandos durante todos os encontros da prática. No quadro 1 estão descritos os critérios de escolha das concepções que foram analisadas na pesquisa.

Quadro 1. Critérios de escolha das concepções que foram analisadas na pesquisa.

- Concepções Individuais: Apenas analisadas as concepções pós-PIIN a luz do TDC,
com exceção da última subcategoria (evolução do conceito de pesquisa da
Nanobiotecnologia), nessa as concepções individuais foram investigadas através do
confronto de ambas.
- Concepções por subgrupo: Analisadas através do confronto concepções prévias
e pós-PIIN a luz do TDC.
- Concepções da síntese geral: Analisadas através do confronto entre as
concepções prévias e pós-PIIN a luz do TDC

Para organização da pesquisa quanto à preservação da identidade dos participantes, cada licenciando recebeu um número o qual foi usado durante toda a pesquisa, servindo de indicação do mesmo na escrita de suas concepções.

Para facilitar as análises os licenciandos foram codificados pela letra $\mathrm{L}$ seguida de um número, partindo-se de L1 até L18. Os Licenciandos que não aparecem nessa lista foram aqueles que iniciaram a PIIN, porém foram excluídos pela ausência durante algumas atividades.

A segunda fase consiste na exploração do material, onde o pesquisador se debruça sobre o corpus da pesquisa e procura codificar, decompor e enumerar em função das regras previamente estabelecidas (BARDIN, 2009).

Com base nesta fase é possível elencar as categorias de análise; sendo as teóricas já estabelecidas a priori e são elas (TDC como recurso para abordagens do "Mundo Nano"), as empíricas segundo os dados coletados na pesquisa sendo essas (Interdisciplinaridade, atualização e Nanoeducação), dessas foram desdobradas as seguintes subcategorias (Abordagens Interdisciplinares, temas contemporâneos e a evolução do conceito de pesquisa da Nanobiotecnologia).

Segundo Bardin (2009), precisamos elencar as unidades de registro, sendo representadas por palavras, temas, acontecimentos e outros; também é preciso identificar as unidades de contexto (unidades que contextualizam extraídas dos sujeitos de pesquisa) que fundamentam as unidades de análise. Ambas são analisadas através das últimas fases que são: o tratamento dos resultados, inferências e interpretação.
Todavia, por questões de espaço do referido artigo, expomos com mais detalhe a primeira subcategoria (Abordagens interdisciplinares); já as outras, (temas contemporâneo $e$ a evolução do conceito de pesquisa da Nanobiotecnologia) estão apresentadas apenas as inferências, que cada análise possibilitou fazer através da coleta de concepções dos licenciandos.

\section{Categoria empírica: Interdisciplinaridade}

Subcategoria: Abordagens Interdisciplinares

Unidade de registro: Ultrapassando os limites disciplinares

As concepções coletadas mostram a compreensão interdisciplinar do "Mundo Nano", mas especificamente da Nanobiotecnologia, sendo unânime nas falas dos licenciandos que tais conhecimentos se fundamentam em teorias e técnicas da medicina e que através dessa fusão têm-se ganhos significativos nas ciências médicas, no que diz respeito aos diagnósticos, prevenção e tratamentos de várias doenças.

Segundo França (2005) os temas sobre Nanotecnologia, em sua essência, não podem ser contemplados à luz de uma única disciplina, sendo necessária ao professor uma abordagem interdisciplinar.

A seguir vamos apresentar as concepções do subgrupo 1.Suprimimos o subgrupo 02 e 03 por questões de espaço.

\section{- CONCEPÇÕES POR SUBGRUPOS $\rightarrow$ SUbgrupo 01:}

No relato desse subgrupo, percebemos que em ambas as concepções (prévia e pós-PIIN) apenas fazem relação dos conhecimentos da Nanotecnologia com os conhecimentos da medicina e farmacologia, porém os TDC discutidos na PIIN extrapolaram esses conhecimentos a outras áreas. Entendemos que os licenciandos poderiam ter realizado outras conexões da Nanotecnologia com outras áreas. Porém como tal abordagem não ficou explicita, podemos dizer que sobre a interdisciplinaridade concepções prévias e pós desde subgrupo, ocorreram de forma ainda incipiente:

Trará novas formas no tratamento de doenças e manipulação de células (Concepção prévia-Subgrupo 01). Otimização do tratamento e diagnósticos de doenças, por meio e nanoestruturados, que protegem os medicamentos [...] (Concepção pós-Subgrupo 01).

\section{- CONCEPÇÃO DA SÍNTESE GERAL}

Em ambas concepções, verificamos a permanência da relação da Nanotecnologia com a robótica (Nanorobôs), chips, produção de remédios (Nanofármacos), medicina (tratamento de doenças, diagnósticos), e a gastronomia (extensão do prazo de validade). Somando a essas abordagens a concepção pós PIIN á luz do TDC, trouxe à tona as relações da Nanotecnologia com a Cosmetologia (Protetores solares).

\section{INFERÊNCIA 01:}

Segundo Fazenda et al. (2011), em uma experiência interdisciplinar, todo aglutinamento em torno da ideia de realizar um trabalho interdisciplinar, por sua vez, exige a transposição de barreiras ideológicas e administrativas. Assim nos apoiando nas concepções discutidas e na citação acima, inferimos que as abordagens nanotecnológicas á luz do TDC, possibilitou uma visão interdisciplinar dos conteúdos, que ultrapassando barreiras disciplinares e quebrando paradigmas permitiram uma maior integração do conhecimento. 


\section{Categoria empírica: Atualização \\ Subcategorias: Temas contemporâneos \\ Unidade de registro: Nanotecnologia aplicada à \\ Nanobiotecnologia e à Nanomedicina}

\section{INFERÊNCIA 02:}

É através da importância em levar aos alunos conhecimentos sobre temas contemporâneos e ainda que envolvam temáticas sobre saúde, é que tal unidade de registro foi elencada. Pois percebemos nas concepções dos licenciandos a recorrente ação em associar os conhecimentos da Nanobiotecnologia na promoção da melhoria da saúde da sociedade.

Após analisarmos junto a alguns teóricos as concepcões individuais, nos 03 subgrupos e a síntese geral inferimos que as práticas norteadas por temas contemporâneos permitem a visualização de novos paradigmas, como a nanobiotecnologia, possibilitando a atualização das aulas de modo que especificamente conteúdos sobre biologia, programa de saúde e outros, possam ter maior significado aos alunos quando relacionados a temas atuais disponíveis e interligados com outros conhecimentos como propôs os TDC.

Assim, concordando com Oliveira e Zancul (2014), a escola é, por excelência, um local propício à divulgação de novas ideias e ao desenvolvimento de ações que envolvam temas contemporâneos de áreas diversas como por exemplo, temas relacionados às questões de saúde.

\section{Categoria empírica: Nanoeducação \\ Subcategoria: Evolução do conceito de Pesquisa da Nanobiotecnologia \\ Unidade de registro: Exemplificação de avanços científicos da Nanobiotecnologia}

\section{INFERÊNCIA 03:}

Tomando como base os dados coletados, inferimos que a abordagem nanotecnológica á luz do TDC, viabiliza a evolução de conceitos complexos pouco explorados em aulas tradicionais quebrando paradigmas consolidados, como afirma Salem e Kawamura (1996) citados por Conceição e Nogueira (2014), os quais dizem que o TDC, pode contribuir para enriquecer a aula trazendo novas questões, abrindo a visão de ciência e de mundo do aluno e professor, criando novas metodologias e recursos de ensino, localizando o conteúdo ensinado em contextos mais abrangentes, motivando e mesmo aprofundando determinados assuntos.

França (2005) reforça essa afirmação, dizendo que se observa que as produções desenvolvidas a partir do "Mundo Nano" trazem inúmeros benefícios para a humanidade, logo a sociedade, deve buscar desenvolver uma cultura científica, para que além de se inteirar sobre as pesquisas atualmente desenvolvidas nesse âmbito, também possam interpretar de maneira coerente as informações que tem acesso, rompendo assim, com paradigmas vigentes.

\section{CONCLUSÕES}

Após a realização da Prática Interventiva Interdisciplinar a luz do Texto de Divulgação Científica (PIIN à luz do TDC) e a discussão dos dados coletados com licenciandos na mesma, foi possível tecer várias considerações sobre esta pesquisa, cujo objetivo foi de analisar as possibilidades de perspectivas interdisciplinares das abordagens da Nanobiotecnologia á luz do TDC dentro de uma Prática Interventiva Interdisciplinar (PIIN).

A aplicação da SDI como instrumento metodológico para coleta de dados facilitou nossa análises à luz da técnica de Analise de Conteúdo (AC) proposta por Bardin (2009). Ainda quanto à aplicação da Sequência Didática Interativa (SDI), prévia e pós a PIIN à luz do TDC, também nos permitiu identificar as concepç̃es prévias e pós-prática, permitindo realizar um confronto de tais concepções. Dessas concepções, concluímos que a abordagens da Nanobiotecnologia a luz do TDC incorporado a PIIN, permitiu trabalhar em sala de aula os conteúdos sob aspectos interdisciplinares, viabilizando a conexão entre os conhecimentos, ultrapassando os limites disciplinares.

Diante do exposto, concluímos que o TDC, possui potenciais e benefícios na realização de PIIN, através de temáticas da Nanobiotecnologia.

\section{REFERÊNCIAS}

BARDIN, L. Análise de conteúdo. (L. A. Reis \& A. Pinheiro. Trad.). São Paulo: Edições 70. Livraria Martins Fontes, 2009.

BRASIL, Agência Brasileira de Desenvolvimento Industrial. Panorama da nanotecnologia no mundo e no Brasil. Brasília: ABDI, 2011, in: Série Cadernos da Indústria ABDI, 21.

BRASIL SCIENTIFIC AMERICAN. Anéis de fogo. $n^{\circ} 156$, Ano 13, 2015, p. 27-35

CHAVES, A. Nanociência e Nanotecnologia. Brasília, DF: Ministério da Ciência e

Tecnologia, 2002. Reportagens. Disponível em:

<http://ftp.mct.gov.br> acesso em: 10 de março de 2015.

CONCEIÇÃO, A. P. S.; NOGUEIRA, R. A. 0 texto de divulgação científica no ensino de ciências: uma abordagem de questões ambientais. In: Encontro de Pesquisa Educacional em Pernambuco, V EPEPE, Garanhuns, 2014.

FAZENDA, I. A. et al. 0 que é interdisciplinaridade?. São Paulo: Cortez, 2008

FAZENDA, I. A. et al. Práticas Interdisciplinares na escola. São Paulo: Cortez, 2011.

FRANÇA, S. B. O desenvolvimento da concepção de Nanomundo no ensino fundamental, 2005. Dissertação (Mestrado em Educação das Ciência), Universidade Federal Rural de Pernambuco, Recife, 2005.

OLIVEIRA, M. M.. Sequência Didática Interativa: No processo de formação de professores. Petrópolis- RJ, Ed. Vozes, 2013. OLIVEIRA L. L.; ZANCUL, M. S. Textos de divulgação científica (TDC) nas aulas de biologia na educação de jovens e adultos (EJA) para abordar a temática alimentação. Revista Práxis, ano VI, $\mathrm{n}^{\circ}$ 11, 2014.

OLIVEIRA, I. S.; VIEIRA, C. L. Física hoje uma aventura pela natureza: dos átomos ao Universo, Rio de Janeiro: Instituto ciência Hoje: Centro Brasileiro de Pesquisas Físicas, 2007. 